\title{
Experimental study on the diffusion of respirable particulate matter in street valley under elevated roads
}

\author{
Hanli Feng ${ }^{1, a}$, Jingde Zhao ${ }^{2, b}$, Zhiyuan $\mathrm{Li}^{3, \mathrm{c}}$ \\ ${ }^{1}$ College of Environmental Science and Engineering, Donghua University, Shanghai 201620, China \\ ${ }^{2}$ College of Environmental Science and Engineering, Donghua University, Shanghai 201620, China \\ ${ }^{3}$ College of Environmental Science and Engineering, Donghua University, Shanghai 201620, China \\ aemail:2151309@mail.dhu.edu.cn, bemail:zhaojingde@dhu.edu.cn , \\ cemail:13262799910@163.com
}

Keywords: street canyon; viaduct; $\mathrm{PM}_{2.5} ; \mathrm{PM}_{10} ;$ particulate mass concentrations; field measurements

\begin{abstract}
In order to the research on the diffusion of the particles in street canyons under elevated roads, field measurements of the diffusion of respirable particles were carried out, which conducted at different heights, atmosphere temperatures and the vegetation coverage. At the same time, the correlation analysis was introduced. The results show: particulate mass concentration in street canyons is negatively correlated with height, respirable particulate matter concentration first decreases with increasing height and increases suddenly over the elevated road; particulate mass concentrations in the street canyon is negatively correlated with blast temperature, with the increase of atmospheric temperature, particulate mass concentration in street canyons is gradually reduced. The greater the degree of vegetation coverage near the building, the more significant the blocking effect of the building below the three story building.
\end{abstract}

\section{Introduction}

Along with the development of urban traffic, there are more and more street canyons under elevated roads, and the elevated roads has influenced the diffusion of particulate matter in street canyons. XIE et al.[1] have applied the standard k- $\varepsilon$ model carrying on a systematic research on distribution of contaminants in street canyons, and the influence of solar radiation on the pollutant diffusion is obtained. Jiang Dehai et al.[2] have used Fluent to calculate the effect of the elevated roads on the $\mathrm{CO}$ concentration in street canyons, and think that the elevated roads on the emission sources will increase the air pollution in street canyons. Wang Yuancheng et al [3] have found the pollutant convection diffusion model of the vehicle emission in urban street canyons, and the accuracy of the model was verified by simulating. Zhou Hongchang et al.[4] has conducted wind tunnel experiment to get the difference of the shape of the street canyon and the influence of different wind direction on the distribution of pollutant concentration. Liu Dameng et al.[5] have measured the concentration of $\mathrm{PM}_{10}$ and $\mathrm{PM}_{2.5}$ in Beijing, the results show that the air velocity is in inverse proportion to the pollutant concentration and Humidity is in proportion to concentration. Afiq Witri Muhammad Azid et al.[6] have used the numerical simulation method to analyze the flow structure and pollutant dispersion in urban street canyons under different physical conditions. Apostolos papathanassiou et al.[7] have applied the model of SEP-SCAM to simulate the distribution of pollution levels in any height of street and the conclusions have a good consistency with the data. A.Ghenu[8] of France has used the model of OSPM to simulate the pollutant concentrations in street canyons and to predict the concentration of traffic emissions. Liedtke et al.[9] conducted a wind tunnel experiment which is used to study the convection diffusion of pollutants and the difference of the different structures of street canyons was obtained. Chan et al.[10]conducted experimental research which concluded the concentrations of $\mathrm{PM}_{2.5}$ and $\mathrm{PM}_{10}$ show exponential distribution along the vertical direction.KUMAR et al.[11-12] measured the distribution of 5 1000 nm particles in the street canyon and the effect of wind speed, wind direction 
on the diffusion of particles. Based on the current domestic researches about field measurement for street canyons with elevated roads are relatively less, therefore, it is necessary to study the street canyon under elevated roads.

In this paper, the experimental monitoring of the diffusion of the particulate matter in the street canyon covered by the elevated road was carried out. At the same time, the correlation analysis was introduced. In order to get the change law of the concentration of the particles in the street canyon, different heights ,temperatures and vegetation coverage were considered.

\section{Site of field measurement for particulate matter}

The street canyon for monitoring located in Zhongshan Road of Changning district in Shanghai, China. The geographical position of the experimental section is shown in Figure 1.On both sides of the street canyon are most commercial buildings and residential areas.

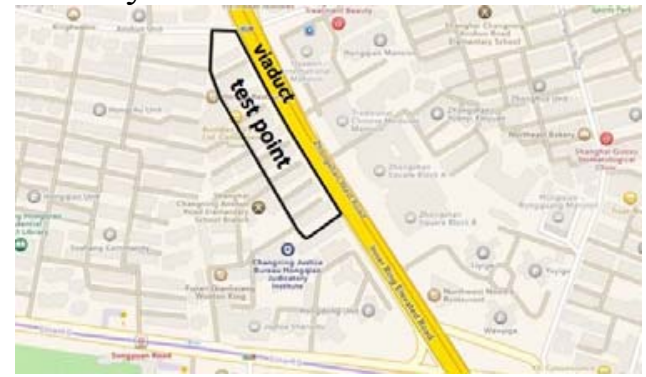

Fig. 1 The status of the test section

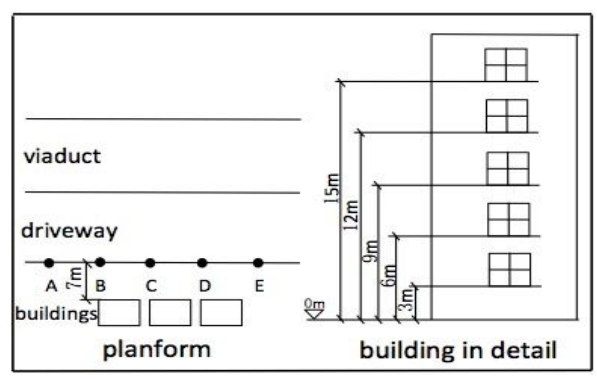

Fig.2 Street canyon with a viaduct

\section{Experimental method}

\section{Layout of measurement points.}

The measuring points are selected in the residential building corridor window having $7 \mathrm{~m}$ from elevated roads measuring point. There are $3 \mathrm{~m}$ between two points and the first measuring point is $3 \mathrm{~m}$ from the ground. The sampling point is arranged at the housing estate called Hongyi besides the elevated road(Figure 1). Sampling points are arranged as shown in Figure 2.

\section{Experimental apparatus.}

The measuring instrument called DustTrak made by the company of TSI in the United States. Its measuring range is in the range of 0.001 to ${ }_{10} \mathrm{mg} / \mathrm{m}^{3}$ and traffic is in $1.7 \mathrm{~L} / \mathrm{min}$. We use KANOMAX (Model KA23) hot wire gauge to measure wind speed and wind temperature and its wind speed range is $0 \sim 50 \mathrm{~m} / \mathrm{s} \pm 2 \% \mathrm{FS}$ and wind temperature range is $-20.0 \sim 100.0^{\circ} \mathrm{C}$.

\section{Experimental procedures.}

The measurements take six days under different weather conditions in April 2015 and May. Temperature variation range was 21 to $30^{\circ} \mathrm{C}$ and the wind speed range is $0.2 \sim 1 \mathrm{~m} / \mathrm{s}$. The site is located in Zhongshan Road of Changning district in Shanghai. In order to clearly record the concentrations of particulate matter in the street canyon under elevated roads, the sampling time is from 9 a.m to $10 \mathrm{a} . \mathrm{m}$. The sampling interval is $1 \mathrm{~s}$, and the sampling time is $2 \mathrm{~min}$ at every point. The measuring points are distributed evenly in the road next to the roads, and the distance between each point is $18 \mathrm{~m}$, the height from the ground is the height of the respiratory surface $(1-1.5 \mathrm{~m})$.

\section{Data processing of particle concentration}

Because of the influence of many factors on the particle concentration in the street canyon near the viaduct, and the weight of each factor is different, in order to analyze the relationship between the environment of the street canyon and the size of particulate matter as well as speculate or demonstrate the sources of the particulate matter, now regression analysis are applied for them.

\section{Data processing of street canyon height and particle concentration.}

In order to explore the relationship between the height of street canyon and the concentration of particles, we chose five measuring points(Figure 2)-F,H,I,J,G at a certain site and get different 
concentrations of $\mathrm{PM}_{10}$ and $\mathrm{PM}_{2.5}$ in the street canyon. The data used is an average of the particulate matter concentration in the viaduct and the street canyon for a certain time. The results are shown in Table 1.

Table 1 The actual concentration of viaduct and street canyon

\begin{tabular}{lllllll}
\hline $\begin{array}{l}\text { Particulate } \\
\text { matter }\end{array}$ & $\begin{array}{l}\text { Dust } \\
\text { source }\end{array}$ & First floor & $\begin{array}{l}\text { Second } \\
\text { floor }\end{array}$ & Third floor Fourth floor Fifth floor \\
\hline $\mathrm{PM}_{2.5}$ & 0.284 & 0.276 & 0.231 & 0.213 & 0.218 & 0.202 \\
\hline $\mathrm{PM}_{10}$ & 0.31 & 0.299 & 0.272 & 0.218 & 0.222 & 0.205 \\
\hline
\end{tabular}

From table 1 we can see that the lower the position in the street canyon, the higher the concentration of the particles. At the same time with the increase of height, the concentration of particulate matter is decreased. The reason lies in the fact that the ground temperature is higher when carrying out the field measurements, and the street canyon is symmetrical. When the sun shines on the ground, the buoyancy increases the vortex motion and the vortex strength increases. Upward floating air current will Influence main air flow and distribute the main air flow into two counter rotating vortices. At the same time, under the action of the gravity of the particles themselves, it will cause particle in low position a higher concentration. Under the action of the reverse vortex, the concentration of particulate matter decreased gradually with the increase of height.

\section{Data processing of ambient temperature and particle concentration in the street canyon.}

In order to explore the relationship between the temperature and the concentration of particles, we chose five measuring points(Figure 2) - A,B,C,D,E at a certain site and get different concentrations of $\mathrm{PM}_{10}$ and $\mathrm{PM}_{2.5}$ in the street canyon. The data used is an average of the particulate matter concentration in the viaduct and the street canyon for a certain time. The results are shown in Table 2.

Table 2 The actual concentration of street canyon and temperature

\begin{tabular}{cccc}
\hline Concentration & $\begin{array}{c}\text { Temperature } \\
\left(21^{\circ} \mathrm{C}\right)\end{array}$ & $\begin{array}{c}\text { Temperature } \\
\left(26^{\circ} \mathrm{C}\right)\end{array}$ & $\begin{array}{c}\text { Temperature } \\
\left(32{ }^{\circ} \mathrm{C}\right)\end{array}$ \\
\hline $\mathrm{PM}_{2.5}$ & 0.283 & 0.278 & 0.272 \\
\hline $\mathrm{PM}_{10}$ & 0.31 & 0.293 & 0.282 \\
\hline
\end{tabular}

From the table 2, the higher the ambient temperature, the lower the concentration of the ambient particulate matter.The cause of this result is that, with the increase of temperature, the heat flux increases and the hot gas flow goes upward. When temperature decreases, the above phenomenons will be reversed.

\section{Effect of vegetation coverage.}

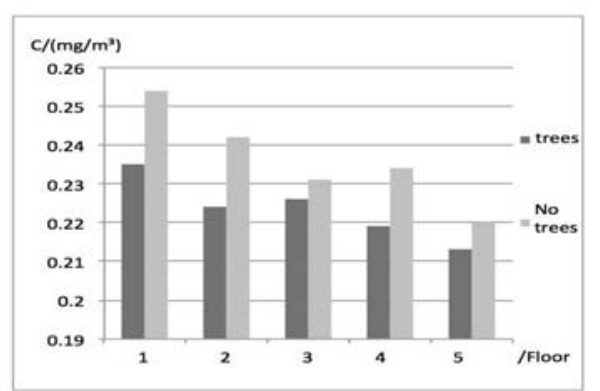

Figure a $\mathrm{PM}_{2.5}$ concentration contrast

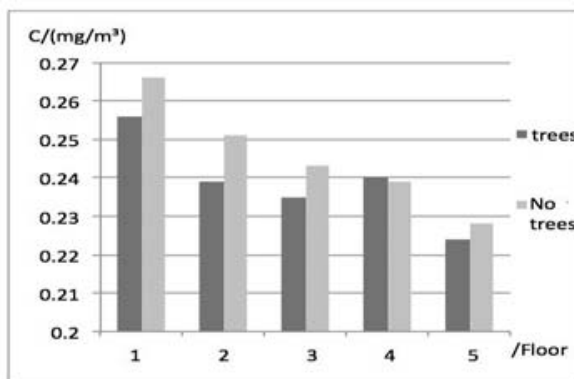

Figure $\mathrm{b} \quad \mathrm{PM}_{10}$ concentration contrast

Fig.3 Street canyon mass concentration changes with different levels of vegetation cover 


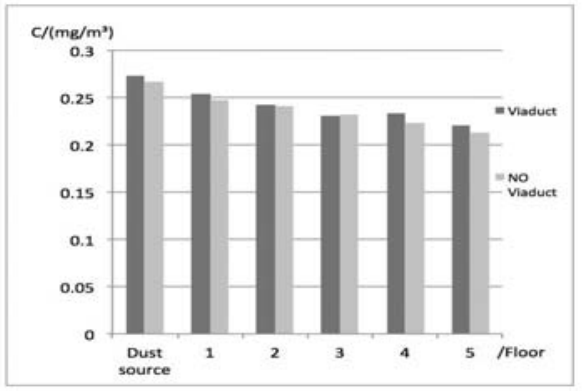

Figure a $\mathrm{PM}_{2.5}$ concentration contrast

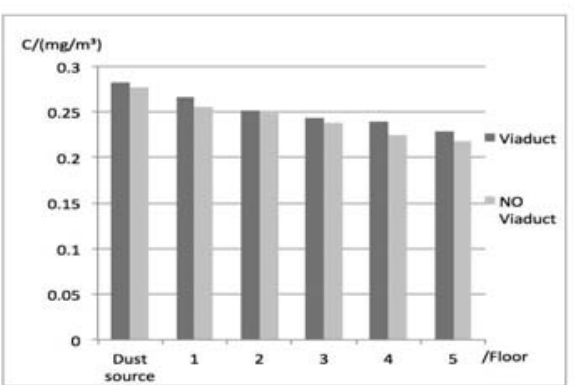

Figure $\mathrm{b} \quad \mathrm{PM}_{10}$ concentration contrast

Fig.4 Street canyon mass concentration changes with the presence of viaduct

From the picture, we can know that the same distance from pollution sources in the elevated roads,below the three floor areas, $\mathrm{PM}_{10}$ and $\mathrm{PM}_{2.5}$ with high degree of vegetation cover were significantly lower than those of the lower vegetation cover.The reason is that $60 \%$ of vehicle emissions are carbon particulate.Therefore, in the area of high vegetation coverage can effectively prevent the spread of pollutants.

\section{Effect of viaduct.}

From the diagram, there is no difference between the existing of the viaduct and the concentration of particulate matter. However, when an elevated roads exists, the concentration of particles in the street canyon is slightly higher than that of the non-elevated roads and in the presence of an elevated roads, there is a sudden increase of the concentration in the height of $12 \mathrm{~m}$, and there is no such phenomenon when there is no viaduct. The cause of this result is that the buildings in the street canyon are not symmetrical, The measuring point is located at the edge of the low side of the building and the points which Located at the height of the $12 \mathrm{~m}$ are near the viaduct. When the wind blows to the higher side of the building, due to the block, the wind blows to the back road viaduct, and then blown to the lower building.

\section{Correlation analysis of particle concentration}

Correlation between concentrations and street canyon heights.

According to the data in Table 1 and the measured data not listed in this paper,we conducted correlation calculation with the linear concept of one element regression. The results are shown in Table 3.In the table,the independent variable of fitting equation of $\mathrm{PM}_{10}\left(\mathrm{PM}_{2.5}\right)$ is street canyon height and the dependent variable is the average mass concentration of $\mathrm{PM}_{10}\left(\mathrm{PM}_{2.5}\right)$ in the street canyon.From the table 1 and table 3,we can get the fitted curves for correlation of the street canyon height and particle concentration(as shown in Figure 5).

Table 3 The correlation of $\mathrm{PM}_{10}$ andPM 2.5 in height and street canyon

\begin{tabular}{ccccc}
\hline $\begin{array}{c}\text { Particulate } \\
\text { matter }\end{array}$ & $\begin{array}{c}\text { correlation } \\
\text { coefficent } \mathrm{r}\end{array}$ & $\begin{array}{c}\text { slope } \\
\text { of } \\
\text { curves }\end{array}$ & Fitting curve & $\begin{array}{c}\text { Adjustment } \\
\text { coefficient }\end{array}$ \\
\hline $\mathrm{PM}_{2.5}$ & -0.708 & -0.00572 & $y_{1}=0.2502-0.00572 x_{1}$ & 0.8415 \\
\hline $\mathrm{PM}_{10}$ & -0.958 & -0.00716 & $g_{1}=0.308-0.00716 \mathrm{x}_{1}$ & 0.8772 \\
\hline
\end{tabular}

From table 2 we can see that the correlation coefficient $r$ value of fitting equation is in the range of $-0.708 \sim-0.9726$ and the correlation coefficient $-\mathrm{R}$ of the fitting equation of $\mathrm{PM}_{10}$ is in the range of $-0.958 \sim-0.979$. These can explain that the correlation coefficient between the height of the street canyon and the particle concentration in the canyon is very high.

Correlation between concentrations and temperatures in the street canyon.

By regression analysis, we get the correlation between five points-A,B,C,D,E(Figure 1)near viaduct and $\mathrm{PM}_{10}$ and $\mathrm{PM}_{2.5}$ in the street canyon. The data used is the average of the particulate 
matter concentration of the elevated roads in a certain time. The results are shown in Table 3.In the table,the independent variable of fitting equation of $\mathrm{PM}_{10}\left(\mathrm{PM}_{2.5}\right)$ is ambient temperature and the dependent variable is the average mass concentration of $\mathrm{PM}_{10}\left(\mathrm{PM}_{2.5}\right)$ in the street canyon.

Table 4 The correlation of $\mathrm{PM}_{10}$ andPM 2.5 in temperature and viaduct

\begin{tabular}{ccccc}
\hline $\begin{array}{c}\text { Particulate } \\
\text { matter }\end{array}$ & $\begin{array}{c}\text { correlation } \\
\text { coefficent } r\end{array}$ & $\begin{array}{c}\text { slope of } \\
\text { curves }\end{array}$ & Fitting curve & $\begin{array}{c}\text { Adjustment } \\
\text { coefficient Adj. } \mathrm{R}^{2}\end{array}$ \\
\hline $\mathrm{PM}_{2.5}$ & -0.998 & $\begin{array}{c}-0.00132 \\
8\end{array}$ & $\hat{y}_{\mathrm{t}}=0.2802-0.00572 x_{1}$ & 0.991 \\
\hline $\mathrm{PM}_{10}$ & -0.951 & $\begin{array}{c}-0.00307 \\
4\end{array}$ & $\hat{y}_{\mathrm{t}}=0.2802-0.00572 x_{1}$ & 0.915 \\
\hline
\end{tabular}

From the data in the table, the temperature is negatively correlated with the concentration of the ambient particulate matter.And from table 4 we can see that the absolute value of the correlation coefficient $-\mathrm{R}$ of the fitting equation of $\mathrm{PM}_{2.5}$ and $\mathrm{PM}_{10}$ is very close to 1.These also can explain that the correlation coefficient between the height of the street canyon and the particle concentration in the canyon is very high.

\section{Conclusions}

The conclusions have concluded through experimental analysis and the correlation between the height of the street canyon and the particle concentration, the temperature and the particle concentration near the viaduct:

a) Because of covering of elevated road, the concentration of particles in the street canyon is higher than that without an elevated road;

b) With the increase of height, the concentration of particulate matter decreased gradually. There is a sudden increase of the concentration in the height of $12 \mathrm{~m}$, and there is no such phenomenon when there is no viaduct. The correlation between the height of the street canyon and the concentration of particles in the canyon is negative;

c) With the increase of the environmental temperature, the concentration of particulate matter decreased gradually. The correlation between the environmental temperature in the street canyon and the concentration of particles in the canyon is negative;

d) The concentrations of PM10 and PM2.5 on the area which covered high degree of vegetation are significantly lower than those of the vegetation cover.

\section{Acknowledgement}

The authors gratefully acknowledge the financial support from the Natural Science Foundation of Shanghai (No. 13ZR1401500).

\section{References}

[1] XIE Xiaomin, HUANG Zhen, WANG Jiasong. Impact of building configuration on air quality in street canyon[J]. Atmos Environ, 2005, 39(35): 4519-4530

[2] JIANG Dehai, JIANG Weimei, MIAO Shiguang. Numerical simulation of airflow and pollutant distribution in urban street canyon[J].Environmental Science Research,2006,19(3):7-12

[3] WANG Yuancheng, WU Wenquan, ZHANG Yi. Numerical simulation of vehicle emission pollutants in street canyons[J].Journal of University of Shanghai for Science and Technology.2004.26(4):150-154

[4] ZHOU Hongchang, WU Xiaosuo. Wind tunnel test and numerical calculation of turbulent flow in street canyons[J].Journal of air dynamics.2000.(SI):27-33 
[5] LIU Dameng, HUANG Jie, GAO Shaopeng, MA Yongsheng, AN Xianghua.Atmospheric particulate matter pollution level and its influencing factors in Beijing urban area[J].Frontier Science.2006.(02):228-233

[6] Afiq Witri Muhammad Yazid, Nor Azwadi Che Sidik, Salim Mohamed Salim, Khalid M Saqr. A review on the flow structure and pollutant dispersion in urban street canyons for urban planning strategies. Simulation,August 2014,Volume 90 Issue 8

[7] Ioannis Douros, Nicolas Moussiopoulos. A simplified three-dimensional approach to street canyon modelling using SEP-SCAMApostolos Papathanassiou. Environmental Modelling\& Software,March 2008, Volume 23 Issue 3

[8] FranceA. Ghenu, J. -M. Rosant, J. -F. Sini. Dispersion of pollutants and estimation of emissions in a street canyon in Rouen,Environmental Modelling\& Software,March 2008. Volume 23 Issue 3

[9] Liedtke J.Leitl B.Schatzmann M.1999.Dispersion in a street canyon: comparison of wind tunnel experiments with eld measurements. In Borrel. PM. Borrel. P. (Eds). Proceedings of the EUROTRAC Symposium 98.WIT Press.Southampton.pp.806-810

[10] L.Y.Chan.W.S.Kwok.Vertical dispersion of suspended particulates in urban area of Hong Kong.Atmospheric Environment.2000:34:4403-4412

[11] KUMAR P,FENNELL P,BRITTER R.Measureme- nts of particles in the 5-1000 nm range close to road level in an urban street canyon[J]. Sci Total Environ,2008,390(2/3):437-447

[12] KUMAR P,FENNELL P,BRITTER R. Effect of wind direction and speed on the dispersion of nucleation and accumulation mode particles in an urban street canyon[J]. Sci Total Environ, 2008,402(1):82-94 